\title{
White, College-Student, Social-Justice Ally Experiences
}

\author{
Jon Cleveland ${ }^{1 *}$, Sharon K. Anderson ${ }^{2 *}$ \\ ${ }^{1}$ Colorado State University, Fort Collins, USA \\ ${ }^{2}$ School of Education, Colorado State University, Fort Collins, USA \\ Email: *jon.cleveland@colostate.edu, *sharon.anderson@colostate.edu
}

How to cite this paper: Cleveland, J. and Anderson, S.K. (2021) White, College-Student, Social-Justice Ally Experiences. Open Access Library Journal, 8: e7629. https://doi.org/10.4236/oalib.1107629

Received: June 10, 2021

Accepted: July 9, 2021

Published: July 12, 2021

Copyright $\odot 2021$ by author(s) and Open Access Library Inc.

This work is licensed under the Creative Commons Attribution International License (CC BY 4.0).

http://creativecommons.org/licenses/by/4.0/

\section{(c) (i) Open Access}

\begin{abstract}
This study explored the question, "How do white, college-student, social-justice allies describe their interactions and relationships with anti-inclusive family and friends?" Data revealed five key themes: regularly witnessing anti-inclusive interactions, regularly confronting anti-inclusion, regularly not confronting anti-inclusion, experiencing strained and lost relationships, and having parameters placed on them. Additionally, using critical whiteness as a theoretical framework, the results furthered our understanding of the phenomenon of whiteness, as well as uncovered several tenets of white supremacy manifested through the participants' interactions and relationships: minimization of racism, white action and complacency, white privilege, and rules of whiteness.
\end{abstract}

\section{Subject Areas \\ Education \\ Keywords \\ College Student, Critical Whiteness, Social-Justice Ally, White Supremacy}

\section{Introduction}

As researchers, we assert that white people must play a stronger role in social justice, and also in acknowledging and dismantling attitudes and behaviors of white supremacy and the power that system asserts over people of color [1]. To effectively engage white college students in social justice, further research is needed to provide a basis for better understanding their experiences. There is a significant gap in our understanding of white, college-student, social-justice allies' experiences navigating interactions and relationships with anti-inclusive 
(racist, homophobic, xenophobic, etc.) family and friends [2]. Toward that objective, the first author [2] addressed the following research question in the current study: "How do white, college-student, social-justice allies describe their interactions and relationships with anti-inclusive family and friends?"

Following the guidance of qualitative researchers [3], the first author used an interpretivist and qualitative approach to hear how participants experienced and interacted with their social world and the meaning the interaction had for them. Through the interpretivist and qualitative lens, truth and reality are constructed by the participants. In the current study, using the participants' (white college student social-justice allies') interpretation of their experiences to generate meaningful data provided the best answer to the research question.

\section{Literature Review}

\subsection{Research Related to White, College-Student, Social-Justice Allies}

Empirical research that directly explores the experiences of white, college-student, social-justice allies in their interactions and relationships with anti-inclusive family and friends is very limited. Interactions, most often include the experiences of allies as they challenge others within their current social and academic circles, are explore first.

A researcher [4] developed the privileged identity exploration model, which, through a qualitative study of nine graduate student participants, identified eight defensive modes that white people display when engaged in difficult discussions around social justice. They [4] found some white people deny their privilege, some deflect away from their own privilege towards a systemic issue over which they can claim no control, and others intellectualize the issue instead of owning the personal aspects of privilege. Additionally, some participants rely on a religious or personal principle to avoid exploration, others display affection for a marginalized group instead of exploring one's own socialization, some are benevolent and focus on how their individual acts of goodness are enough to avoid further exploration, and, finally, some participants minimize the magnitude of the issue.

A team of researchers [5] offered insight into strategies for effectively facilitating difficult dialogues around social justice. The researchers conducted a qualitative study of 14 white counseling psychology graduate students, aiming to identify strategies for more effectively facilitating difficult classroom discussions. Using focus groups as the interview tool, they found instructors could more effectively engage students in these discussions when they validated the feelings of the students and allowed space to explore those feelings. Similarly, conversations were deemed most effective when the instructors were open about their own learning and owned any of their personal biases and feelings. Finally, many negative discussions were tied to a lack of action on the part of the instructor where a discriminatory statement or microaggression happened and it went unad- 
dressed. It was important for instructors to do something, even if the response was less than perfect.

In 2010, researchers [6] interviewed a diverse (age, education level, and geographic location) range of 18 white adults who self-identified as antiracists about their participation in a range of activities supporting that self-identification, including organizing activities, filling leadership roles in relevant organizations, and speaking out in everyday situations against discrimination. Through their work, the researchers identified several strategies white antiracists used for reaching out to other white people. An initial finding was white antiracists just had to speak up and find ways to overcome any hesitation, which takes a conscious commitment. Additionally, those with privileged identities must have the confidence to challenge problematic behavior because they can easily sit silent in the face of discrimination. They found white antiracists also varied their intervention with anti-inclusive white people based on the perpetrator's level of knowledge, finding ways to be respectful but also challenge, remain patient, and capitalize on teachable moments. The antiracists also attempted to connect other white people to antiracist allies and organizations for support, motivation, and community, and also encouraged participation in race-related trainings.

Finally, researchers [7] offered a "new strategic framework developed for addressing microaggressions that moves beyond coping and survival to concrete action steps and dialogues that targets, allies, and bystanders can perform (micro-interventions)" (p. 128). They [7] reviewed existing common reactions and interventions deployed by those reacting to a microaggression (retreating, remaining passive, striking back, validating and supporting the target, and so on) and grouped all those reactions into four major strategic goals: 1) making the invisible visible; 2) disarming the microaggression; 3) educating the perpetrator; 4) seeking external reinforcement or support. These data represented additional context for understanding the interactions with anti-inclusive family and friends.

Regarding relationships specifically, another finding within the previous study [6] was that white allies experienced interpersonal conflict in many of their relationships as a result of their antiracist activity. These conflicted relationships were not only with general acquaintances, but also included significant fallouts with family and friends. Another study [8] had similar findings, including struggles to make and maintain relationships and being alienated by others. The researchers conducted a qualitative study to learn how white antiracists defined their racial identities and related lifestyle choices. Ten individuals participated in the study, split equally between men and women, and ranging in age from 25 69. Participants were spread throughout the United States. Two additional findings related to lifestyle choices added new context to the experiences of white allies, including struggles to make lifestyle decisions that honor antiracist beliefs and struggles to make and maintain relationships with other white people.

In looking at relationships allies hold, researchers [9] conducted a quantitative 
analysis assessing a person's relationship type with others as strong (parents, friends) vs. weak (stranger or casual acquaintance), against a willingness to engage in political discussions. Using a national volunteer sample, the researchers surveyed 2,381 individuals from a diverse pool. There were several findings, including people were more likely to share a political affiliation with someone with whom they have a close relationship, and were more likely to engage in political discussions with those with whom they share a strong relationship. They also found participants were more likely to express disagreement with those with whom they share a close relationship. This is important because there are likely parallels to the research question, as political discussions may include issues related to social justice. If students are more likely to express disagreement with those with whom they share a strong personal relationship, there are implications for confronting anti-inclusive beliefs with anti-inclusive family and friends.

The preceding section of research is the material most closely related to the research question and helpful for both laying a foundation for this study and offering a glimpse into the experiences of white, college-student, social-justice allies and their experiences navigating interactions and relationships with others that are anti-inclusive.

\section{Methodology}

\subsection{Population and Sample Identification}

The first author [2] conducted the research at an institution in the western part of the United States with a student population of more than 30,000. The campus is a predominantly white institution, with many students from surrounding, homogenously white communities. Although the campus population is mostly white, there are many opportunities for students to engage in social-justice-related activities.

In phenomenological research, the goal is to describe the structure of an experience, not the characteristics of the group who had the experience [10]. An additional researcher [11] reaffirmed phenomenology is not about making generalizations, quantifying data, or making a definitive finding. The methodology is not about precise and objective measures. Instead, the goal in research under a phenomenological paradigm is to develop a deeper, richer understanding of the phenomenon under study.

Thus, the sample size means fewer participants and allows the researcher to focus on the participants' individual experiences [12] [13] through in-depth interviewing that fully captures the experiences of the participants [14]. Qualitative research uses nonprobability sampling to deliberately select participants who reflect features or characteristics within the sampled population [15]. Therefore, the number of participants is dependent upon the nature of the research problem and research methodology [16]. Recruitment of participants is appropriate to uncover a range of experiences regarding the research question until saturation occurs and redundancy of data is achieved [16]. 
The first author [2] contacted professionals who were, directly and indirectly, engaged in social-justice-related work and activity within the institution to recommend white, college-student, social-justice allies. In addition to being identified by professionals in social-justice-related work as white, social-justice allies, potential participants were assessed through a screening-interview protocol conducted by the first author. All potential participants were asked about their understanding of the concepts such as racism (including systems), power and privilege. In addition, they were asked about experiences such as social-justicerelated workshops, classes, trainings, and diverse groups of friends.

\subsection{Data Collection}

The first author [2] conducted a two-part (90 minute each), semi-structured interview with each participant. Both content mapping (identifying and exploring the issues most relevant to the study) and content mining (exploring the details within each issue) questions were used [15]. Examples of content mapping questions included, "Tell me more about your interactions and relationships with family and friends that don't share your beliefs," and "What, if any, are the changes in relationships you have experienced as a result of intervening and challenging different beliefs?" Each participant chose a unique pseudonym for their name during the interview.

\subsection{Data Analysis}

The analysis of the data included three rounds of coding. Qualitative researchers [17] described data coding as a way to give symbolic meaning to the qualitative data and offer sound recommendations to conduct qualitative data analysis. The three rounds included: provisional coding (first round), subcoding (second round), and analysis against the theoretical framework (third round).

In the first round, provisional coding included entering the data analysis with researcher-established codes; the codes included those representing what might appear in the data based on prior knowledge or preparation. The provisional codes were established around the content-mapping questions and themes in the interview protocol. In the second round, subcoding was used when needed after the provisional coding was completed; this subcoding allowed for the inclusion of further detail and the capability to differentiate or enrich the initial data classification [17]. At times, no further subcoding was necessary for a specific data point.

The third round of coding included comparing both the raw data and organized thematic data against the theoretical framework of critical whiteness through the use of pattern codes related to the theoretical constructs of whiteness. Studying white, social-justice allies could be problematic. This type of research grants space and power to white people who have already been granted a disproportionate amount of space and power. We used critical whiteness as a theoretical framework to address this concern. Beyond examining the interac- 
tions and relationships between the participants and their anti-inclusive family and friends, the findings were also viewed through the lens of critical whiteness to further expose some of the complexities of white supremacy.

Rather than waiting until all interviews were completed to analyze the data, the data analysis occurred alongside data collection. This approach allowed for concurrent thinking and reflection about the existing data, the collection of new and better data in subsequent interviews, and the capability to assess when data saturation had been reached. The writing, discussing, and reflecting was a cyclical process that ultimately brought the participants' experiences to life, deepened the existing knowledge of the phenomenon of whiteness, and answered the research question [18].

\section{Results}

A total of 14 students were screened, and 12 students were included in the study. The two prospective participants not included in the study were excluded because they both explained they did not feel they had any significant interactions with anti-inclusive family or friends. The interviews of the 12 participants provided sufficient redundancy to achieve saturation.

\subsection{Demographics}

The following table provides demographic information. See Table 1 below.

\subsection{Results for Research Question}

An examination of the data revealed five themes: anti-inclusive interactions; confronting; not confronting; strained and lost relationships; and parameters.

Table 1. Participant summary.

\begin{tabular}{|c|c|c|c|}
\hline Participant Pseudonym & Year in School & Gender & Age \\
\hline Alex & $4^{\text {th }}$ & Male & 21 \\
\hline Atticus & $4^{\text {th }}$ & Male & 22 \\
\hline Bryn & $2^{\text {nd }}$ & Male & 21 \\
\hline Chris & $4^{\text {th }}$ & Trans Non-Binary & 22 \\
\hline Grace & $3^{\text {rd }}$ & Female & 20 \\
\hline John & $3^{\text {rd }}$ & Male & 20 \\
\hline Lindsay & $3^{\text {rd }}$ & Female & 22 \\
\hline Maggie & $4^{\text {th }}$ & Female & 21 \\
\hline Sam & $3^{\text {rd }}$ & Female & 21 \\
\hline Sophie & $4^{\text {th }}$ & Female & 22 \\
\hline Tommy & $3^{\text {rd }}$ & Female & 21 \\
\hline Tristan & $2^{\text {nd }}$ & Gender Neutral & 19 \\
\hline
\end{tabular}




\subsubsection{Five Themes}

1) Anti-Inclusive Interactions. The participants spoke to a wide range of frustrations when they were interacting with anti-inclusive family and friends. Often, there was an unwillingness on the part of those individuals to engage in social-justice discussions, or they showed active resistance during the conversations. Many of the interactions were also problematic, whether racist, disrespectful toward the participants, or dismissive of the participants' concerns. For instance, when asked to share her answer to the question, "How do you describe interactions with anti-inclusive family?" Maggie offered, "I think they're tense. It's very, I can't think of the right word, but like walking on eggshells, trying to say the right thing and not upset the situation..."

Tristan described their interactions with anti-inclusive family this way: "Summary is that they're abrasive, that they aren't willing to be open about it. And even when you attempt to be open, they don't want to talk about it, and it's a subject that isn't brought up."

Another participant, Chris, generally described their interactions with antiinclusive family and their unwillingness to change as:

Frustrating, I have no less love for them based on that. But especially knowing and being able to witness firsthand other people grow in their capacity for empathy and acceptance, to be in relationships and communication with people who have that same capacity, but just refuse to use it. It's really frustrating, and I try not to let that get to me too much. Because at that point, I don't think anything productive comes from attacking people or making them feel like they have to defend themselves.

The data here are a sample of the many frustrating and problematic experiences the participants had with anti-inclusive family and friends. These experiences included an unwillingness to engage in social-justice discussions, active resistance during the conversations, and comments and beliefs that were antiinclusive and disrespectful towards the participants.

2) Confronting. There were multiple examples of the participants using their voices to challenge anti-inclusive family, friends, and even strangers. Bryn offered an example in which he chose to confront a Cleveland Indians baseball fan over his T-shirt:

I confronted this perceived-to-be white male this other day. He was wearing that Cleveland Indians baseball logo...the Chief Wahoo. It's easier for me to confront perceived-to-be white people too because I feel like maybe they can still listen more. If not, it'll at least maybe plant a seed in their minds. This person didn't react well. He was like, "If you're offended or it offends other people, there's the door. There's the door. There's the door." I was like, if other people can come up to him and say something, then maybe it can make a difference but, obviously, I wasn't expecting my confronting him to change his perception. 
John offered an example of his experience working for his college's newspaper during a time when there was a racist incident on campus. He found himself challenging policies and speaking out against the newspaper's leadership:

I was actually the main person who said, "I think we should actually get an article out about this," and that kind of came from my role at [student newspaper], because I had Black students that I was meeting with who were just extremely upset about this and wanted to know what they could do; and so I kind of felt like I owed it to them to cover this, fully and accurately...So I personally met with the managing editor and editor in chief and I was like, "This is not right."

Maggie shared a story about a vacation with her grandparents, during which her grandfather was being racist toward Asians:

I took a road trip with my grandparents to Yellowstone a couple summers ago. When tourists come to America, Yellowstone is a huge national tourist location. We were camping in Yellowstone, and there was a ton of Asian tourists...My grandpa kept calling them all Japanese. I was like, "That's racist." I was like, “They're not all Japanese.” Then he said something along the lines of, "There's so many Japs here I'm going to need to pull another Hiroshima." I was like, "That's not a joke, and that's not funny." He was like, "Why don't you laugh at it?" I was like, “That's not a funny joke."

When they did confront anti-inclusion, the participants developed strategies to be taken seriously. These specific strategies or approaches with anti-inclusive family and friends resulted in the other person being more open to listening. The most common strategies were 1) not to become angry or upset; 2) to be inquisitive and not immediately shut the other person down; and 3) to use stories that made the conversation personal. Sam highlighted the value of having one-on-one conversations:

I think definitely having one-on-one conversations and intentional conversations...like, "Hey, I noticed you said this. I personally don't agree." Or like, "Can you tell me more about why you think that?" And kind of having that conversation is way more beneficial, regardless if I change someone's mind about something or not. I like to think that we can both come out of that conversation and have learned something or have learned about a different perspective.

Alex offered a powerful quote he shared that he used when talking with people with whom he had differing opinions, "You don't have to be wrong for me to be right." He expressed that the statement removed the perception there is a right or wrong answer in every given situation.

The data reviewed here supported that the participants regularly used their voices to challenge anti-inclusive family and friends. When doing so, the participants found effective ways to be heard. While promising, there was also a strong 
theme suggesting the participants regularly did not use their voices when seeing or hearing something anti-inclusive.

3) Not Confronting. In contrast to the previous theme, the data also suggested the participants regularly chose to remain silent when faced with something anti-inclusive. Chris shared how they regularly choose not to engage around anti-inclusive language:

With triggering language, I'm pretty good at hiding how I feel. It's not the greatest talent to have, but I'm able to hide my reactions and stuff. So if I'm affected, most people aren't going to know. So it depends on how much it impacts me, genuinely. If my dad makes an offhand comment, like using queer as a slur, because he's done that before too, I'm able to brush that off.

When asked about the likelihood of engaging, Chris shared, "At this point, I'm probably trying to engage $30 \%$ of the time and trying not to $60 \%$ of the time." Regarding confrontation, John shared, "It's something that I am definitely getting better with. But it's not something that...I do hesitate a lot.” The participants were easily able to provide examples showcasing anti-inclusion by family and friends. However, the participants could not as easily provide examples of confronting this anti-inclusion. This disconnect seems to suggest that, although it was common for them to hear anti-inclusive language, some participants were regularly choosing to stay silent in many situations.

Participants provided reasons for not confronting anti-inclusive family and friends. These choices were most often grounded in general fear, concern over harming a relationship, or a lack of confidence in their ability to defend their opinion. Maggie shared her hesitancy in calling out family, "It's always hard to call out family. When they say something, you don't want to call them out because you've got to live with them for the rest of your life." John shared his experience with one of his uncles, someone whom he had never confronted over his anti-inclusive beliefs:

One of my uncles is especially a very pro-Trump supporter...you'll usually find him in the dining room at anybody's house arguing something political, and after a while it's...I don't know, it's kind of a lot. But I guess I honestly have not spoken up against what he says because I guess I'm still learning how to do that, and I think if it was somebody who I wasn't related to, who I didn't like...I think if it was anybody else, I would know how to speak up and explain, counter what they're saying. But because he's just so passionate and kind of just spewing fake information, I don't know how to change his mind.

While the data suggesting participants both used their voices and did not use their voices could appear to be conflicting themes, it was important to highlight both. Each theme was supported in the data and gave evidence supporting the conclusion that the participants often did both.

4) Strained and Lost Relationships. Another theme that emerged from the da- 
ta was how relationships with family and friends had changed as a result of the participants' social-justice identities. In some cases, that included the loss of relationships; but more commonly, it included the participants feeling less close to others, intentionally distancing themselves from others, or both. John shared more about his changed relationship with his uncle, who was regularly sharing his anti-inclusive beliefs at family gatherings:

I think my relationship with him has been impacted. I'm not close to him. In the past I might have been a little closer, but I just don't even get involved with him. Which is something I do want to change in the future, to stand up to what he's saying, and all. But overall, I think my relationship has been negatively affected by his conversations and his rhetoric; and I think that is a cost of being a social-justice ally...that you're not always going to have people who agree with you, and that could negatively impact your relationships with your literal family.

As another example, Lindsay chose to remove her mother's access to her social media accounts:

I mean, right now I'm not friends with my mother on social media, and there's the acquaintance setting...you can remove a follower. So I just did that instead of blocking and unblocking...the issues I have and the issues I fight for are not the ones that my mom agrees with.

Grace shared that her commitment to social justice resulted in other people choosing not to have a relationship with her:

I'd say one cost would be like relationships with others...I've had an instance where someone who had certain ideals and beliefs and identified as Christian after I shared my learnings of, "Hey, I want to be inclusive, and that includes everything, gender-identity expression, orientation, others' identities." So by me saying that, and by me showing that I want to be inclusive, I've had relationships where people were like, “Okay; well, that's it. I'm not talking to you. I'm avoiding you." And that relationship was lost. But yes, it was a cost but I've recognized that maybe I don't want to be in that.

5) Parameters. The participants shared examples in which parameters were placed on their social-justice identity. In some cases, the individual participants chose to limit what they shared about both their personal identities and social-justice engagement with others. In other cases, their family set the parameters on what participants should share. For example, Grace disclosed her caution about what she shares with others, and she specifically referenced recognizing that her actions and beliefs also reflected on her family:

It's very much different when we're at the family dinner table versus if we are at church on Sunday morning...I guess I'm more cautious when sharing that because not only do I have a relationship with my family, but my family has a relationship with their friends, and I have a relationship with many of 
them. The dynamic of that...I would not want to say something that would be taken a certain way by them, and then have the three-part-the family, me and their friends-that whole dynamic. I wouldn't want people to get frustrated for no reason.

Although Maggie did not set parameters around what she shared with her immediate family, there were parameters in place around what was shared with her extended family:

When I came out, somehow my grandma on Facebook found out about it...

Then within the next day the whole family knew about it. It's just unspoken that nobody talks about that; or there's parameters, like if I have a partner, I don't bring them to family gatherings...parameters around my extended family, what you can and can't talk about, what you can't do, participate in, things like that. It's very clear for extended family.

The five thematic findings further our understanding of the experiences of white, college-student, social-justice allies' interactions and relationships with anti-inclusive family members and friends. The participants regularly experienced anti-inclusive interactions, were both regularly confronting and not confronting anti-inclusion, experienced strained relationships, and had parameters placed on them. However, the themes are only part of the story; they also highlight the phenomenon of whiteness. Using a theoretical framework of critical whiteness, we contextualize the participants' experiences within a broader system in our discussion below.

\section{Discussion}

To frame the discussion, we have used two analytical questions: "Where do the findings support or negate the existing literature?" and "How does critical whiteness inform the findings?" These analytical questions suggest four critical intersections.

\subsection{Critical Intersections}

Four critical intersections were uncovered: the minimization of racism, white action and complacency, white privilege, and rules of whiteness. These are discussed below.

\subsubsection{The Minimization of Racism.}

Viewing the current study's findings through the lens of critical whiteness revealed the participants' minimization of racism. Several of the well-intentioned strategies participants deployed, including not becoming too angry or upset, being inquisitive, and not shutting the other person down, can easily contribute to the minimization of racism. In addition, the minimization of racism was revealed in the findings through statements such as "But she's a good person and doesn't mean anything by it." Another example was when participants uninten- 
tionally normalized racism. For example, one of the participants talked about his extended family this way:

But I don't think they really understand that that kind of conversation, that that kind of language is racist, because I don't think they ever really had people kind of explain that to them and point that out. And so it's just so normalized in their conversation that it's just like they don't even realize what they're saying.

The minimization of racism suggests that discrimination and racism are no longer important factors affecting minorities' chances at life. This belief allows whites to accept things such as hate crimes and other prejudicial treatments and actions as minorities being hypersensitive and pushing a nonexistent racial agenda [19]. The minimization of racism, even while one is challenging someone anti-inclusive, demonstrates the complex nature of white supremacy as a belief system and how it is upheld in our society. To adequately get anti-inclusive family and friends to listen to them, most participants used one or more of the strategies previously mentioned. Those strategies, in turn, both minimized what the anti-inclusive family member or friend was saying, and also granted them unfair latitude to engage in racism.

\subsubsection{White Action and Complacency}

White action refers to the actions white people take when confronted with anti-inclusion. The actions of participants in the current study most often included challenging an anti-inclusive comment verbally or using a nonverbal cue to signal disagreement. Supporting existing research [5], the participants also confirmed validating feelings, being open about their own learning, and owning personal biases and past mistakes as effective strategies when interacting with anti-inclusive family and friends. While this advocacy is good, a critical whiteness analysis reminds us that people of color have been using their voices for much longer, more loudly, and regularly not receiving any credit. Similarly, focusing on critical whiteness also reminds us to reflect on the participants' actions in this study and where even more could and should be accomplished. It is easy to become complacent as an ally.

White folks cannot just speak out when it is convenient. That option only perpetuates a culture of white supremacy. Simply speaking out will not change anti-inclusive policies and systems [20]. White people must take greater action. Consistently speaking out is only one piece of the puzzle; taking action also includes organizing, protesting, writing politicians, making social-justice-centered monetary decisions, and partnering with people of color to force change to happen. A few of the participants did offer these examples; however, they were limited. The findings suggest that while white, college-student, social-justice allies do take action, white privilege also allows them to withdraw from taking action without significant impact on their lives. 


\subsubsection{White Privilege}

Comparing the theme that the participants often did not use their voices to challenge something anti-inclusive with the idea that silence is oppressive presents another example of how even social-justice allies can be in collusion with white supremacy. The results of this study include many examples of participants not using their voices in the face of something anti-inclusive-possibly even more examples than when they used their voices. The capability of participants to opt in and out of challenging anti-inclusive family and friends without having that choice directly impact the day-to-day experience of those making the choice is a manifestation of white privilege.

White people have a responsibility to speak up. The choice not to take the initiative to use their voices when something anti-inclusive arises is not as simple as ignoring something. That decision has much larger implications, including their using white privilege to avoid taking action, and supporting white-supremacist behavior through silence and collusion with the perpetrator of the anti-inclusion. When people make racist or other anti-inclusive comments and the bystanders remain silent, that silence is perceived as agreement. A piece that describes "silent racism" [21] suggested that it is critical for white people to use their voices to challenge other white people because it is in the absence of people of color that the most racist comments are likely to be made (p. 51).

\subsubsection{Rules of Whiteness.}

The impact that being a social-justice ally has on relationships with anti-inclusive family and friends was a central theme in this study. More specifically, the finding that participants often set parameters, or had parameters set for them around how they shared their personal marginalized identities and social-justice values, has further implications within critical whiteness. For example, a participant reflected on her extended family and shared, "I've always been careful with what I reveal about myself to people...If you don't want to start something bad, you've got to keep it to yourself." Similarly, regarding her sexual orientation and gender identity, another participant's father told her, “Oh; you shouldn't tell everybody about this," so the participant often withheld sharing that information. The phenomena of whiteness contains conscious and unconscious norms and cultural expectations, including unwritten rules for how whites engage with other white people, all of which perpetuate patterns of white supremacy. A researcher [22] has exposed some of these dynamics:

White allies may be labeled "White liberal" troublemakers, isolated by fellow White colleagues, threatened to be disowned by family members, or risk not obtaining a raise or promotion they had hoped to receive...Ironically, as nonracist and antiracist identities are developed, the traditional support groups of family, friends, and colleagues often no longer play supporting roles. In fact, they can serve the opposite function of forcing allies to be silent or to return to their old ways (p. 714). 
This theme highlights some of the cultural norms and expectations around the phenomena of whiteness and white supremacy. White people are not supposed to talk about social justice, or to challenge anti-inclusive white people. White people who do challenge are seen as outsiders and can experience costs, including lost and damaged relationships, associated with their decision to use their voices. The parameters set by the participants or others, usually immediate family, demonstrate another way that white-supremacist beliefs and practices are maintained, through the active governing of how white people interact and engage with other white people around social-justice matters-namely, the expectation that challenging anti-inclusion be avoided.

In conclusion, this study's findings have increased our understanding of the experiences of white, college-student, social-justice allies in their interactions and relationships with anti-inclusive family and friends and furthered our understanding of the phenomena of whiteness and the magnitude and complexity of white supremacy. The data analysis and findings of this study suggest that the experiences of white, college-student, social-justice allies are robust and sometimes difficult to navigate. Many of the same powerful influences that uphold beliefs about and patterns of white supremacy also make being an ally challenging. It can be challenging to take action against other white people in the face of anti-inclusion. Doing so can result in the loss of a friendship or a strained relationship with a family member. Allies must navigate a complex set of rules that govern expectations of white people and ultimately uphold beliefs and actions that support white supremacy.

The positive actions of white, college-student, social-justice-ally participants should be acknowledged and encouraged. Ultimately, this is what we want as faculty and staff in higher education: more white college students engaging in social-justice advocacy and creating inclusive spaces. However, support for white supremacy is powerful, allies still contribute to white-supremacist beliefs and behaviors, and we all have a lot more work to do. "Whiteness is a many-faceted phenomenon, slowly and constantly shifting its emphasis, but all the time maintaining a racial hierarchy and protecting the power that accrues to white people" [20] (p. 23). When silent, allies use and promote white privilege. Similarly, even when taking action, an ally can minimize racism by using strategies to make the perpetrator more open to hearing what they are saying. And even white allies are subject to the many ways that a system of whiteness is rendered invisible in our society. Well-intentioned allies still participate in a white-supremacist system.

\subsection{Delimitations and Limitations}

The primary delimitation was the decision to use critical whiteness as the theoretical framework after the interviews and during the coding process. This was a conscious decision by us as the researchers. We chose to collect data, gain a general sense of the findings, and then make a decision about a theoretical framework that seemed appropriate. There were costs associated with that decision. 
Had we chosen the framework prior to the interviews, we might have crafted the content-mapping questions slightly differently or followed-up differently with the content-mining questions, both of which could have provided additional data.

The primary limitation of this study was the specific sample of white, college-student, social-justice allies. As with qualitative research, the results of this study are not generalizable beyond the specific participants. While not generalizable, qualitative research does produce vast amounts of detailed and rich data from a smaller number of cases [23]. The findings from this study are useful in informing the ways we conduct social-justice work and help practitioners better support white college students engaging in social-justice work.

\section{Implications, Future Research, and Conclusion}

\subsection{Implications for Practice}

Specific areas for consideration emerged with regard to white, college-student, social-justice allies: training, support, and challenge. Our training strategies in higher education (whether academic classes or co-curricular experiences) have additional opportunities to better impact white allies. More attention should be paid to teaching white allies how to take action, the importance of taking action consistently, and preparing them for the challenges from other white people they may experience when taking action. As discussed, the data here suggested the participants regularly chose not to take any action in the face of anti-inclusion because of fear, lack of confidence, and other outlined reasons. Those are missed opportunities to educate others and, at minimum, set expectations about acceptable behavior with anti-inclusive family and friends.

Second, the findings from this study suggested that practitioners can provide more intentional support to white allies. The participants in the study experienced damaged and lost family relationships and friendships. Those changes in relationships, and other examples, including having parameters set on how they share their personal and social-justice identities and receiving limited or no support from family, are all examples of places white allies may need support.

Third, the findings from this study suggest the pervasive nature of whiteness, including white supremacy, even in those who self-identify as white social-justice allies. Most of the participants held a marginalized identity, most often around, sexual orientation gender identity, and ability. It might be that for these participants their marginalized identity was a major focus for their social justice ally work. Practitioners working with students who identify as white allies and have marginalized identities might challenge them to pause and think about their whiteness and how their whiteness maintains "a racial hierarchy" and is a protection of "power that accrues" to them as a white person [20] (p. 23).

\subsection{Recommendations for Future Research}

The findings from this study provide the basis for understanding how white college students think about and describe their interactions and relationships 
with anti-inclusive family and friends. However, there are areas of scholarship that should be explored in the future. Researchers could examine the role that marginalized identities play in white, college-student, social-justice allies' commitment to social justice. In addition, a study could explore how white, collegestudents, social-justice allies, those with and without marginalized identities, conceptualized their whiteness. Lastly, research could better address how white, college-student, social-justice allies take action when they see social-injustice occurring and what helped them do so.

\subsection{Conclusion}

A total of 12 white, college-student, social-justice allies shared their interactions and relationships with anti-inclusive family and friends to answer the research question: "How do white, college-student, social-justice allies describe their interactions and relationships with anti-inclusive family and friends?" Five themes emerged through data analysis: anti-inclusive interactions, confronting, not confronting, strained and lost relationships, and parameters. In addition, we garnered the additional understanding of the phenomena of whiteness even among those who identify as social-justice allies. Looking through the lens of critical whiteness, four critical intersections were uncovered in the experiences shared: the minimization of racism, white action and complacency, white privilege, and rules of whiteness. The presence of white supremacy is certainly in our current culture.

\section{Conflicts of Interest}

The authors declare no conflicts of interest.

\section{References}

[1] Tochluk, S. (2008) Witnessing Whiteness: First Steps toward an Antiracist Practice and Culture. Rowman \& Little-Field Education, Lanham, MD.

[2] Cleveland, J. (2020) Using phenomenology and Critical Whiteness to Understand the Experiences of White College-Student Social-Justice Allies and Their Interactions and Relationships with Anti-Inclusive Family and Friends (Doctoral Dissertation). ProQuest Dissertations and Theses Database. Colorado State University, Fort Collins, USA.

[3] Merriam, S. (2002) Introduction to Qualitative Research. In: Merriam, S. and Associates, Eds., Qualitative Research in Practice, Jossey-Bass, San Francisco, 3-17.

[4] Watt, S.K. (2007) Difficult Dialogues, Privilege and Social Justice: Uses of the Privileged Identity Exploration (PIE) Model in Student Affairs Practice. College Student Affairs Journal, 26, 114-126.

[5] Sue, D.W., Rivera, D.P., Capodilup, C.M., Lin, A.I. and Torino, G.C. (2010) Racial Dialogues and White Trainee Fears: Implications for Education and Training. Cultural Diversity and Ethnic Minority Psychology, 16, 206-214. https://doi.org/10.1037/a0016112

[6] Smith, L. and Redington, R.M. (2010) Lessons from the Experiences of White Antiracist Activists. Professional Psychology: Research and Practice, 41, 541-549. 
https://doi.org/10.1037/a0021793

[7] Sue, D.W., Alsaidi, S., Awad, M.N., Glaeser, E., Calle, C.Z. and Mendez, N. (2019) Disarming Racial Microaggressions: Microintervention Strategies for Targets, White Allies, and Bystanders. American Psychologist, 74, 128-142. https://doi.org/10.1037/amp0000296

[8] Malott, K.M., Paone, T.R., Schaefle, S., Cates, J. and Haizlop, B. (2015) Expanding White Racial Identity Theory: A Qualitative Investigation of Whites Engaged in Antiracist Action. Journal of Counseling and Development, 93, 333-343. https://doi.org/10.1002/jcad.12031

[9] Morey, A.C., Eveland, W.P. and Hutchens, M.J. (2012) The "who" matters: Types of Interpersonal Relationships and Avoidance of Political Disagreement. Political Communication, 29, 86-103. https://doi.org/10.1080/10584609.2011.641070

[10] Polkinghorne, D.E. (1989) Pheomenological Research Methods. In: Valle, R.S. and Halling, S. Eds., Existential-Phenomenological Perspectives in Psychology: Exploring the Breadth of Human Experience, Plenum Press, New York, 41-60. https://doi.org/10.1007/978-1-4615-6989-3_3

[11] Vagle, M.D. (2018) Crafting Phenomenological Research. 2nd Edition, Routledge, New York. https://doi.org/10.4324/9781315173474

[12] Creswell, J.W. (2013) Qualitative Inquiry and Research Design: Choosing Among Five Approaches. 3rd Edition, Sage, Los Angeles, CA.

[13] Roberts, T. (2013) Understanding the Research Methodology of Interpretative Phenomenological Analysis. British Journal of Midwifery, 21, 215-218. https://doi.org/10.12968/bjom.2013.21.3.215

[14] Groenewald, T. (2004) A Phenomenological Research Design Illustrated. International Journal of Qualitative Methods, 3, 1-26. https://doi.org/10.1177/160940690400300104

[15] Ritchie, J. and Lewis, J. (2003) Qualitative Research Practice: A Guide for Social Science Students and Researchers. Sage, Thousand Oaks, CA.

[16] Wertz, F.J. (2005) Phenomenological Research Methods for Counseling Psychology. Journal of Counseling Psychology, 52, 167-177. https://doi.org/10.1037/0022-0167.52.2.167

[17] Miles, M.B., Huberman, A.M. and Saldana, J. (2014) Qualitative Data Analysis: A Methods Sourcebook. 3rd Edition, Sage, Thousand Oaks, CA.

[18] Jones, S.R., Torres, V. and Arminio, J. (2014) Negotiating the Complexities of Qualitative Research in Higher Education: Fundamental Elements and Issues. Routledge, New York, NY.

[19] Bonilla-Silva, E. (2006) Racism without Racists: Color-Blind Racism and the Persistence of Racial Inequality in the United States. Rowman \& Littlefield, Oxford, UK.

[20] Kivel, P. (2002) Uprooting Racism: How White People can Work for Racial Justice. Friesens, BC, Canada.

[21] Trepagnier, B. (2006) Silent Racism: How Well-Meaning White People Perpetuate the Racial Divide. Paradigm Publishers, Boulder, Colorado.

[22] Sue, D.W. (2017) The Challenges of Becoming a White Ally. The Counseling Psychologist, 45, 706-716. https://doi.org/10.1177/0011000017719323

[23] Patton, M.Q. (1990) Qualitative Evaluation and Research Methods. 2nd Edition, Sage Publications, Inc., Newbury Park, CA. 